\title{
Achalasia: Insights into Diagnostic and Therapeutic Advances for an Ancient Disease
}

\author{
Amir Mari, M.D. ${ }^{1,2,3}$, Kalp Patel, B.Sc. ${ }^{3}$, Mahmud Mahamid, M.D. ${ }^{1,2}$, Tawfik \\ Khoury, M.D. ${ }^{1,2}$, and Marcella Pesce, M.D. ${ }^{3}$ \\ 'Gastroenterology Institute, Nazareth EMMS Hospital, Nazareth, Israel; ${ }^{2}$ The Azrieli Faculty of \\ Medicine, Bar-Ilan University, Safed, Israel; and ${ }^{3} G I$ Physiology Unit, University College London \\ Hospital, London, United Kingdom
}

\begin{abstract}
Achalasia is a chronic idiopathic disease characterized by the absence of esophageal body peristalsis and by defective lower esophageal sphincter (LES) relaxation. The incidence rate ranges from 1.07 to up to $2.8 \mathrm{new}$ cases per year per 100,000 population. Presenting symptoms include dysphagia, regurgitation, vomiting, and weight loss. The diagnosis of achalasia has undergone a revolution in the last decade due to the advent of high-resolution manometry (HRM) and the consequent development of the Chicago Classification. Recent progress has allowed achalasia to be more precisely diagnosed and to be categorized into three subtypes, based on the prevalent manometric features of the esophageal peristalsis. Treatment options are pharmacotherapy, endoscopic management (Botox injection or pneumatic dilation), and surgery, e.g. laparoscopic Heller myotomy (LHM). More recently, a new endoscopic technique, per oral endoscopic myotomy (POEM), has developed as a less invasive approach alternative to the traditional LHM. Since the first POEM procedure was performed in 2008, increasing evidence is accumulating regarding its efficacy and safety profiles. Currently, POEM is being introduced as a reasonable therapeutic option, though
\end{abstract}

Abbreviations: EGJ, esophagogastric junction; HRM, high-resolution manometry; LHM, laparoscopic Hiller myotomy; POEM, per oral endoscopic myotomy; LES, lower esophageal sphincter; TBS, timed barium-swallow.

Citation: Mari A, Patel K, Mahamid M, Khoury T, Pesce M. AchalasiaAchalasia: Insights into Diagnostic and Therapeutic Advances for an Ancient Disease. Rambam Maimonides Med J 2019;10 (1):eooo8. Review. doi:10.5041/RMMJ.10361

Copyright: (c) 2019 Mari et al. This is an open-access article. All its content, except where otherwise noted, is distributed under the terms of the Creative Commons Attribution License (http://creativecommons.org/licenses/by/3.0), which permits unrestricted use, distribution, and reproduction in any medium, provided the original work is properly cited.

Conflict of interest: No potential conflict of interest relevant to this article was reported.

Acknowledgment: Some of the information in this review was previously published in Hebrew as "Achalasia: Updates in Diagnosis and Management from the Last Decade," HaRefuah, 2018 Oct;157(10):668-671. All figures and images in the current publication are original and have not been previously published.

* To whom correspondence should be addressed. E-mail: amir.mari@hotmail.com 
randomized controlled trails are still lacking. The current review sheds light onto the diagnosis and management of achalasia, with special focus on the recent advances of HRM and POEM.

KEY WORDS: Achalasia, esophagogastric outflow obstruction, high-resolution manometry, per oral endoscopic myotomy (POEM)

\section{INTRODUCTION}

The term "achalasia" originates from the Greek word $a$-khalasis, meaning lack of relaxation. It is a neurodegenerative disorder characterized by the absence of esophageal body peristalsis and by defective lower esophageal sphincter (LES) relaxation. The precise pathogenesis of this condition is poorly understood so far. Nonetheless, recent evidence suggests a possible role of an autoimmune reaction triggered by a viral infection that leads to an inflammatory process and consequent disruption of inhibitory neurons within the myenteric plexus, releasing nitric oxide..$^{1,2}$ Achalasia is a rare disease with incidence rate of 1.63/ 100,000 population, and prevalence of 10/100.000 population, ${ }^{3}$ it is generally diagnosed between the ages of 30 and 60 years, and both genders appear to be equally affected. ${ }^{3}$ Its presenting symptoms are classically dysphagia, regurgitation of undigested food, vomiting, and weight loss. Less typical symptoms are heartburn, chest pain, cough, and choking. The diagnosis of achalasia is usually delayed for many years. The advent of high-resolution manometry (HRM) has largely replaced the traditional conventional manometry. Pressure recording is done by using a catheter with multiple closely spaced pressure sensors that traverses the esophagus and passes through the LES. This permits a colorful topographic presentation of esophageal body peristalsis as well as optimal localization of the LES (Figure 1). This has led to dividing achalasia into three distinct subtypes with different presentation, prognosis, and probably treatment response. ${ }^{-6}$ Additionally, the presence or absence and size of a hiatal hernia can be assessed with HRM, with a higher sensitivity than with endoscopy or radiography alone. ${ }^{7}$

\section{DIAGNOSTIC APPROACH}

The initial diagnostic step to the patient presenting with dysphagia is to rule out any mechanical or anatomic obstruction in the esophagus or at the esophagogastric junction (EGJ). Therefore, endoscopy is necessary to exclude tumors, inflammation, strictures, and other possible causes. ${ }^{8}$ Nearly half of achalasia patients will have suggestive findings of the disease during endoscopy, such as dilated esophagus, food and fluid contents, and difficulty with passing the endoscope through the EGJ. ${ }^{9}$ Bariumswallow serves as a complementary test and may show some morphological features suggestive of achalasia such as esophageal dilation and tapered distal esophagus. Timed barium-swallow (TBS) is an objective method to evaluate esophageal emptying by measuring the height of the fluid column over 5 minutes. Timed barium-swallow often represents a first-line diagnostic tool in patients complaining of dysphagia since it is inexpensive, non-invasive, and does not require special technology or expertise. ${ }^{10}$

Once mechanical or anatomical etiologies for the patient's symptoms are excluded, HRM is the goldstandard investigation to be performed in order to search mainly for achalasia or EGJ outflow obstructtion as well as for other major peristaltic disorders (distal esophageal spasm, jackhammer esophagus, or absent contractility). An integrated diagnostic algorithm summarizing the stepwise approach to patients complaining of esophageal dysphagia is depicted in Figure 2.

\section{RECENT ADVANCES IN THE DIAGNOSIS OF DYSPHAGIA: HIGH-RESOLUTION MANOMETRY}

High-resolution manometry is the gold standard modality in investigating patients complaining of dysphagia, diagnosing achalasia, and defining its subtype, and has largely replaced the traditional conventional manometry, used for the last 60 years. ${ }^{11}$ The HRM catheter contains up to 36 pressure sensors distributed closely $(1 \mathrm{~cm}$ distance from each other) throughout its length. The catheter is introduced through the nares, traverses the esophagus, and passes through the EGJ. Each sensor records pressures during the study, and data are transferred to software. The software utilizes this information to create a visually instinctive topographic spatiotemporal plot of esophageal peristalsis and LES function, where changes in pressure are represented as color variations over a time axis (Figure 1). In 1991 Silny described the utility of intraluminal impedance 

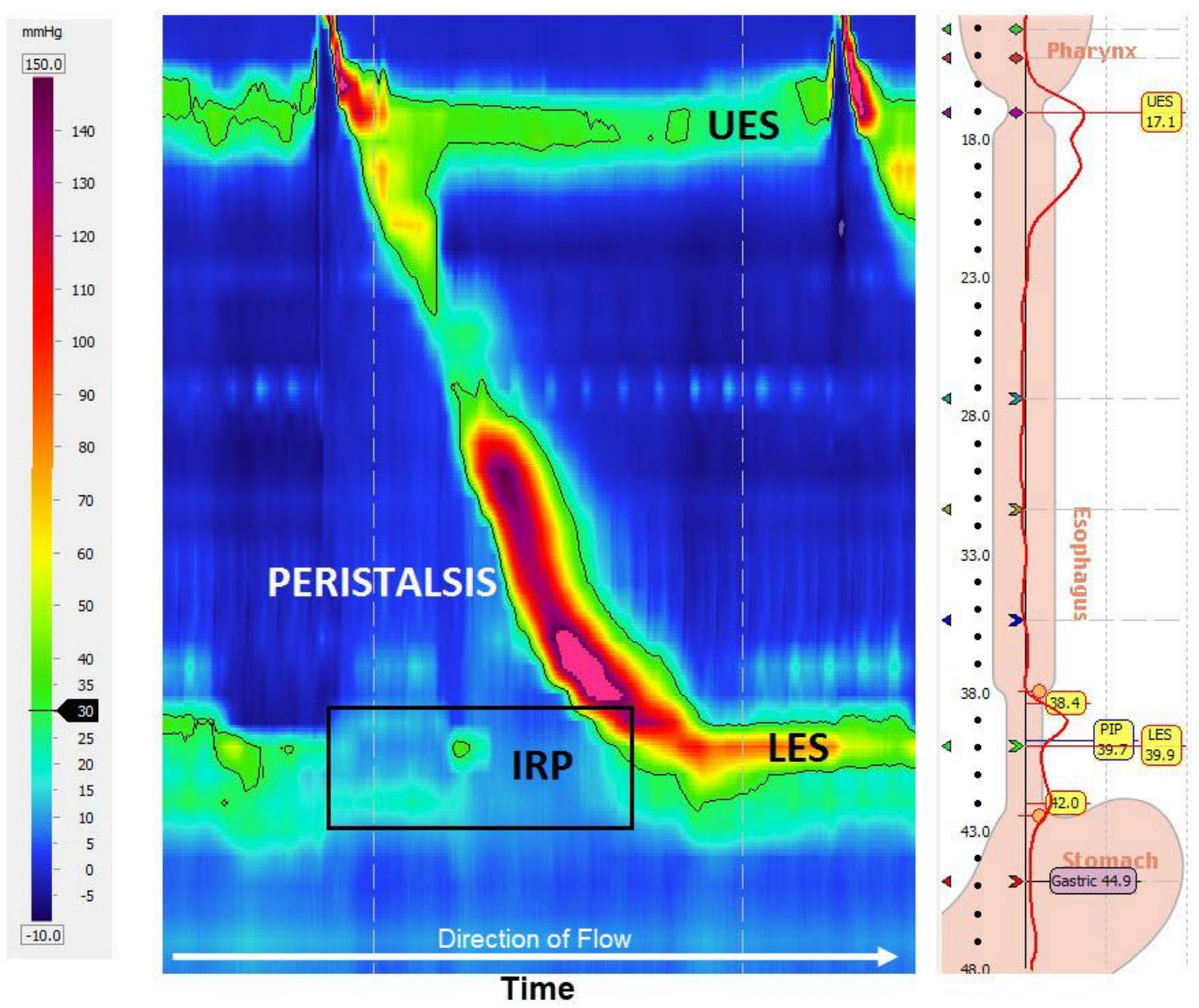

Figure 1. Example of High-resolution Manometry with Esophageal Pressure Topography.

Single swallow initiated at the upper esophageal sphincter (UES) showing normal esophageal body peristalsis and normal lower esophageal sphincter (LES) relaxation; LES relaxation is measured over a 10 second period as indicated by the black box and calculation of the integrated relaxation pressure (IRP).

to assess bolus propagation through the gastrointestinal tract. ${ }^{12}$ The system is based on measurement of electrical impedance (resistance to electrical current conduction), between several electrodes spanning an intraluminal catheter. Intraluminal air has high impedance, whereas liquid has low impedance. The addition of impedance function during HRM study has enabled an objective assessment of bolus movement through the esophagus, which reflects esophageal emptying.

There are several advantages of HRM compared to the old conventional manometry, including: better localization of the LES, shorter study time, less intra-observer and inter-observer variation of study analysis, and, lastly, optimal assessment of esophageal body peristalsis with the ability of detecting even minor peristaltic defects. ${ }^{11-13}$
The development of HRM has allowed the subsequent development of the Chicago Classification, currently at its third iteration, and the subsequent objective classification of esophageal motor disorders, thus improving standardization in the diagnosis and the follow-up of these disorders. ${ }^{14}$ The Chicago Classification is a practical scheme for analyzing and interpreting HRM studies as well as classifying esophageal motility into major and minor disorders. ${ }^{15,16}$ The latest version of the Chicago Classification was finalized in Chicago, USA, during an International HRM Working Group. ${ }^{16}$ This classification was then endorsed by several international motility societies, as an algorithm standardizing the interpretation of HRM studies.

The Chicago Classification subdivides achalasia into three subtypes (Figure 3). The presence of 


\section{Perform EGD to exclude}

intraluminal structural, anatomic, and mucosal causes:

- Esophagitis

- Strictures

- Webs

- Tumors

- Eosinophilic esophagitis

- Rings

- Signs of achalasia

\begin{tabular}{|l|}
\hline Perform HRM to rule out major \\
motor disorders: \\
- Achalasia \\
- EGJ outflow obstruction \\
- Distal esophageal spasm \\
- Jackhammer esophagus \\
\hline
\end{tabular}

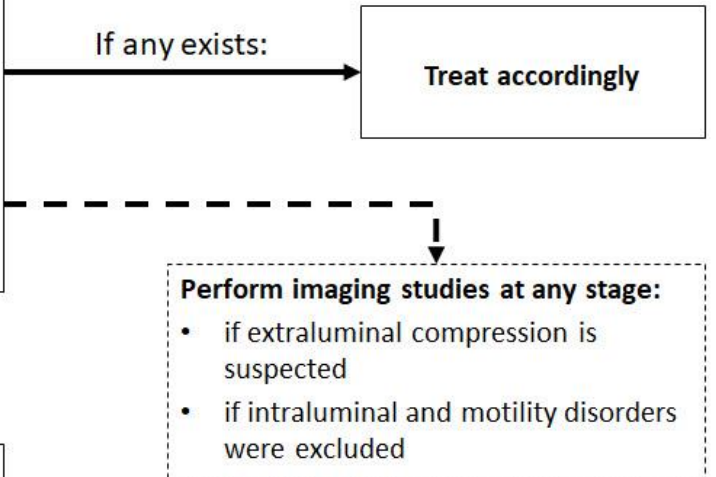

Figure 2. Diagnostic Algorithm in Patients with Symptoms of Esophageal Dysphagia.

EGD, esophago-gastro-duodenoscopy; EGJ, esophagogastric junction; HRM, high-resolution manometry.

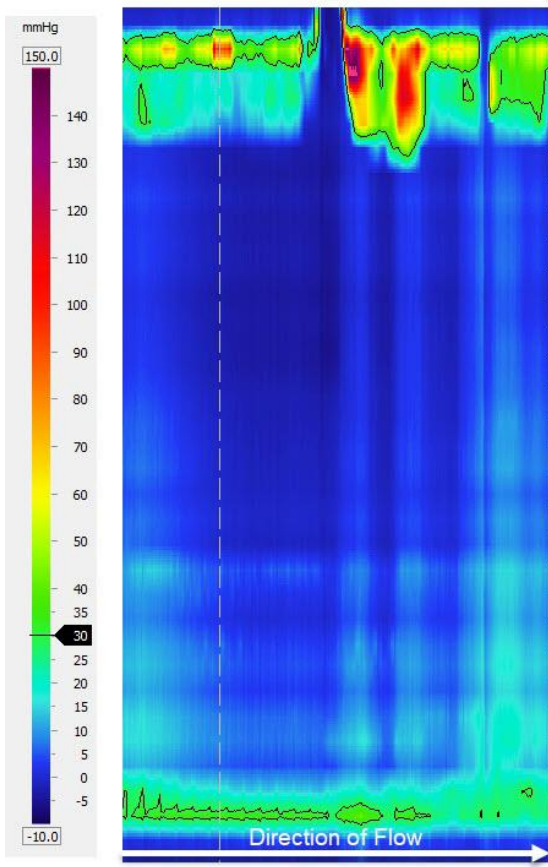

Time

Type I

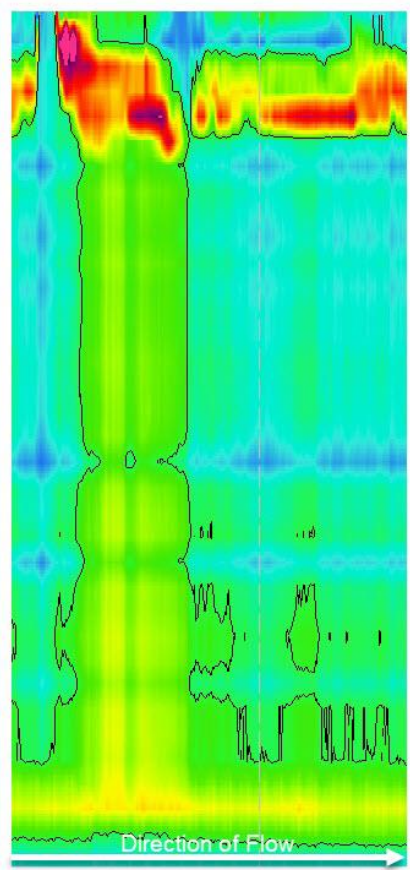

Time

Type II

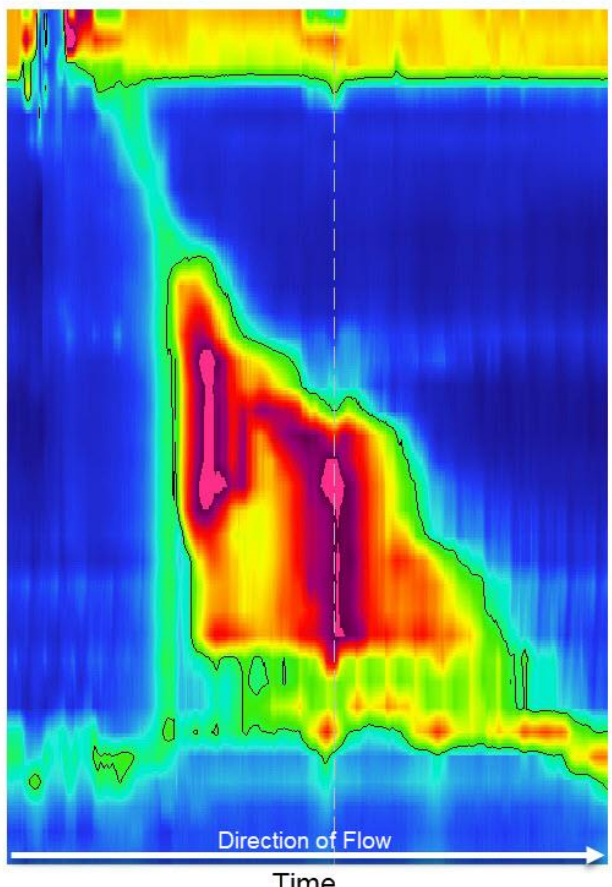

Type III

Figure 3. The Chicago Classification Achalasia Subtypes.

Achalasia type I is characterized by the total absence of peristalsis for all swallows. In type II the peristalsis is replaced by pan-esophageal pressurizations. Type III is characterized by the presence of premature spastic contraction. 
impaired EGJ relaxation is the common denominator of all subtypes with an increased integrated relaxation pressure (IRP), defined as the lowest average relaxation pressure within 10 seconds of LES relaxation window. An increased IRP ( $>15 \mathrm{mmHg}$ ) defines outflow obstruction and resistance to flow at the level of the EGJ. ${ }^{16}$ Achalasia type I is characterized by the total absence of peristalsis for all swallows. In type II the peristalsis is replaced by pan-esophageal pressurizations throughout the tubular esophagus, whilst type III is characterized by the presence of premature spastic contractions. ${ }^{15-17}$ This subdivision of achalasia has led to improved understanding of the different clinical presentations, prognosis, and also impacts on the therapeutic choices, allowing a tailored therapeutic strategy. ${ }^{17,18}$ One of the major observations with the classification of achalasia phenotypes was that treatment outcomes were dependent on phenotype, with outcomes being best in type II, intermediate for type I, and worst in type III. ${ }^{19}$ Rohof and colleagues have shown in a randomized controlled trial that the best treatment outcomes were observed in type I achalasia patients (more than 95\% good treatment outcomes for balloon dilation and Hiller myotomy), while the least successful treatment outcomes were observed in type III achalasia patients (40\% and $84 \%$ good treatment outcomes for balloon dilation and Hiller myotomy, respectively).20

Additionally, the Chicago Classification has introduced a new entity called functional or idiopathic EGJ outflow obstruction-historically known as "variant achalasia." This entity is now more commonly diagnosed due to the advent of HRM and is characterized by the evidence of outflow obstruction at the level of the EGJ, accompanied by normal esophageal body peristalsis (Figure 4). ${ }^{16}$ The diag-

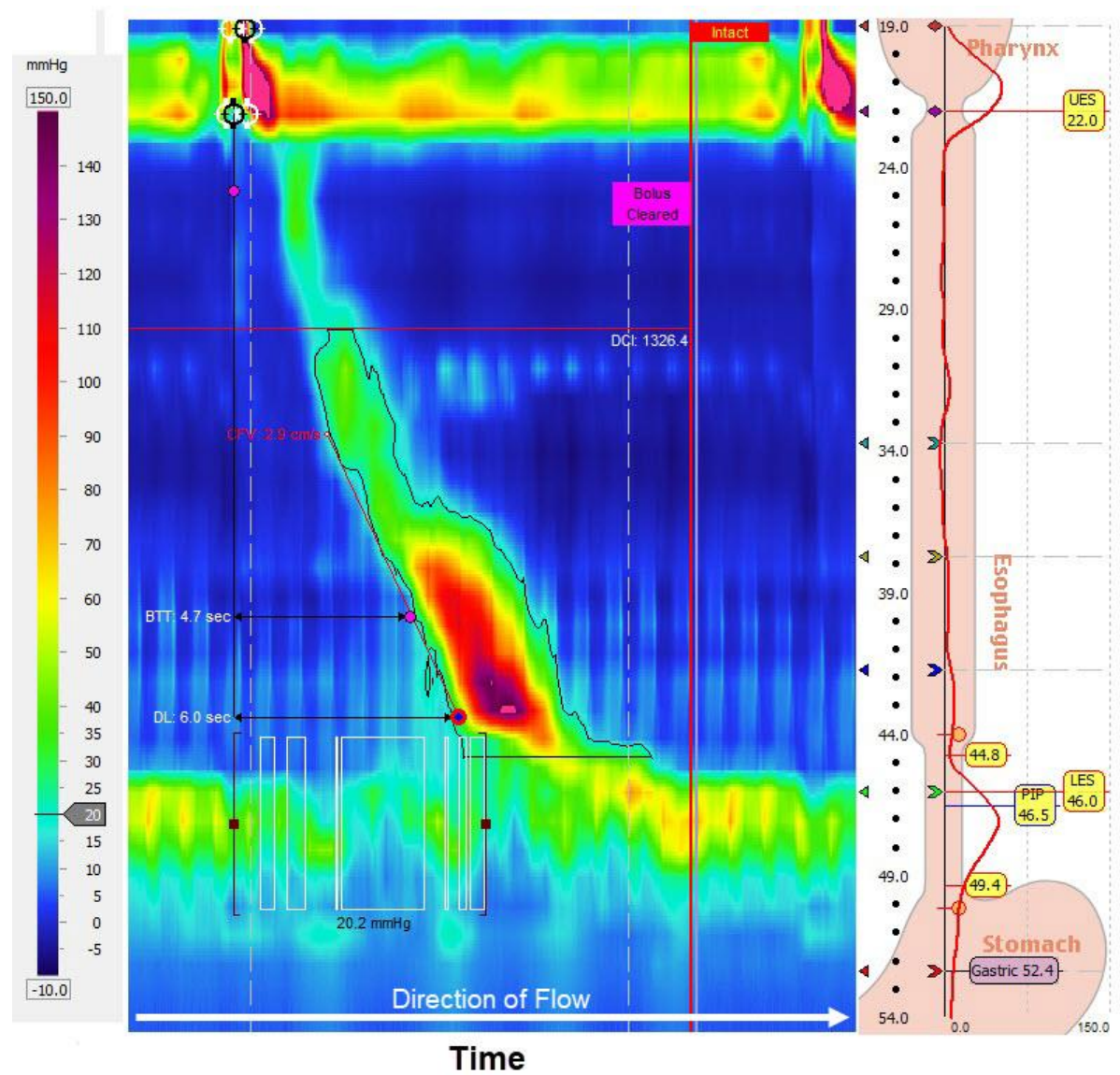

Figure 4. Esophagogastric Outflow Obstruction (EGOO).

Shown is the outflow obstruction at the level of the esophagogastric junction (IRP>15 mmHg), accompanied by normal esophageal body peristalsis. BTT, bolus transit time; CFV, contraction front velocity; DL, distal latency; DCI, distal contractile integrity; PIP, pressure inversion point. 
nosis of EGJ outflow obstruction demands a careful endoscopic and imaging assessment in order to exclude misrecognized mucosal or anatomical pathologies, mainly submucosal tumors, previously known as pseudo-achalasia. ${ }^{21}$ Opiate use has been linked with esophagogastric outflow obstruction, hyperspasticity, and other motor disorders. ${ }^{22-24}$ Hence, it is also important to address that properly during history taking. Some investigators have suggested that functional EGJ outflow obstruction represents an early achalasia. ${ }^{16}$ Nevertheless, although EGJ outflow obstruction is being reported more frequently than achalasia, challenges exist in understanding its etiology, clinical significance, natural history, and appropriate therapy, and more research is warranted to better elucidate these uncertainties.

\section{TREATMENT OPTIONS}

The main aim of achalasia treatment is to reduce patients' symptoms and to improve their quality of life. Achalasia is an irreversible disease, and the restoration of esophageal peristalsis is unreliable. Therefore, the ultimate goal of therapy is to relieve the obstruction at the level of the EGJ by either administering drugs able of inducing LES relaxation (botulinum toxin injection) or by mechanically disrupting sphincter integrity via endoscopic (pneumatic dilatation or per oral endoscopic myotomy [POEM]) or surgical techniques (laparoscopic Heller myotomy [LHM]). The decision regarding the optimal treatment strategy largely depends on the patient's symptoms, comorbidities, age, achalasia type, preference, and the center expertise. ${ }^{25}$

The pharmacological treatment of achalasia includes administration of several muscle-relaxant drugs such as nitric oxide, calcium channel blockers, or sildenafil. However, pharmacological agents have generally limited efficacy, temporary effect, and are associated with adverse events such as headache, edema, and dizziness. ${ }^{26}$ Thus, the use of pharmacological agents is limited to specific clinical situations such as a bridge therapy before more invasive procedures or when the patient is not candidate to invasive therapies.

Botulinum toxin injection at the EGJ has been used for achalasia treatment since 1994. ${ }^{27}$ The main effect of botulinum toxin is to block the release of acetylcholine which ultimately causes the temporary loss of muscle contraction. The main limitation of this treatment is its temporary efficacy, with a drop in symptom relief from $78 \%$ at one month to less than $40 \%$ after one year. ${ }^{28}$ Hence, botulinum toxin injection use is also limited to specific clinical situations such as a bridge therapy before an invasive procedure or for frail patients not candidates for more definitive therapies. ${ }^{29}$

Pneumatic balloon dilation is an effective and safe treatment for achalasia. ${ }^{29}$ During the procedure, an inflatable balloon is passed through the esophagus under fluoroscopic guidance and placed within the LES, and then the balloon inflated up to 10-15 pounds per square inch (PSI) and maintained for 60 seconds, leading to muscle disruption in the LES. The graded balloon dilation approach with increasing balloon diameters ( $30 \mathrm{~mm}, 35 \mathrm{~mm}, 40 \mathrm{~mm}$ ) has been proven to be more efficient and safer, leading to fewer esophageal perforations. ${ }^{30}$ In most centers, pneumatic dilation is performed in two treatments with $30 \mathrm{~mm}$ and $35 \mathrm{~mm}$ balloon dilatations performed 2 to 4 weeks apart. Pneumatic balloon dilation is an efficient and long-lasting treatment, with a success rate of $86 \%$ after 2 years and $85 \%$ after 5 years. ${ }^{30,31}$ The long-term outcomes following pneumatic balloon dilation are comparable to those of LHM after 2 and 5 years. ${ }^{2}$ The main complications of pneumatic balloon dilation are gastro-esophageal reflux disease occurring in $15 \%-35 \%$ of patients, which is generally well controlled by anti-acid medications. ${ }^{11}$ The reported risk of esophageal perforation ranges from $2 \%$ to $4 \%$, and the risk increases with balloon size, limited performer experience, and among men.30,31 Conservative management of esophageal perforations is satisfactory in most cases, with good short- and long-term prognosis. 33

Heller myotomy has been performed for achalasia treatment for more than 100 years. The laparoscopic approach is the currently preferred one. During the surgery, a dissection of the anterior muscle fibers is performed. In order to prevent post-surgical gastro-esophageal acid reflux, a fundoplication is generally done after myotomy. Partial fundoplication, rather than a complete one, is the preferred approach in order to avoid dysphagia. ${ }^{34}$ So far, two types of partial wrap are commonly performed in achalasia patients after Heller myotomy: the posterior $270^{\circ}$ fundoplication (Toupet) and the anterior $180^{\circ}$ fundoplication (Dor). 35 The success rate measured by symptom improvement scores following LHM is estimated to be $85 \%$ after 5 years. ${ }^{6}$ The surgery is safe with very low mortality rate, less than $1 / 1000$. 


\section{NOVEL ADVANCES IN THERAPY: PER ORAL ENDOSCOPIC MYOTOMY (POEM)}

Inoue performed the first POEM in humans in 2008.37 The procedure's objective is to perform LES myotomy during an endoscopic procedure. This is achieved by creating a submucosal tunnel accessed through a mucosal orifice within the esophageal wall, passing through the tunnel into the EGJ region, and then performing myotomy of the circular muscles mainly with an endoscopic knife. ${ }^{38}$ Since the first report published in 2010, numerous case series from all over the world have been published, contributing to the growing knowledge about POEM. Barbieri et al. published a metaanalysis in 2015 of 551 patients, showing a pooled success rate of $93 \%$, though the follow-up period was very diverse and ranged from 3 months to 3 years. 39 The major adverse events of POEM include: hydrothorax, late bleeding, pneumothorax, and intensive care unit admission. The major adverse events rate is $3.3 \%$ as shown in a retrospective study of 1680 Chinese patients. $4^{\circ}$ Analysis of three studies revealed comparable safety and efficacy profiles of POEM in comparison with balloon dilation and LHM, with a main advantage of POEM with shorter hospital stay and recovery time..$^{11}$ Furthermore, it has been hypothesized that POEM could offer a more efficient symptomatic relief for type III achalasia patients in comparison with surgery. ${ }^{42}$ So far, no randomized controlled trials comparing POEM to balloon dilation or Heller myotomy have been performed. The indications of POEM are expanding to include major motility disorders other than achalasia, such as diffuse esophageal spasm and jackhammer esophagus refractory to conservative therapies. Khashab and colleagues showed a 93\% clinical success rate of POEM after a 8-month follow-up period in these patients. 43

To summarize, achalasia is a chronic motor disorder with unknown etiology. The advent of HRM in the last decade has permitted to improve our understanding of esophageal peristalsis and to consequently subclassify achalasia into three groups with different prognoses, providing a tailored therapeutic approach. The introduction of HRM alongside the advent of the POEM procedure, a novel therapeutic option for achalasia, has radically changed the approach to the disorder. The safety and efficacy of POEM have been shown to be comparable to classical techniques such as balloon dilation and surgery. Although these results are encouraging, randomized controlled trials are eagerly awaited to better define the long-term follow-up outcomes of POEM.

\section{REFERENCES}

1. Gockel I, Becker J, Wouters M, et al. Common variants in the HLA-DQ region confer susceptibility to idiopathic achalasia. Nat Genet 2014;46:901-4. Crossref

2. Sarnelli G, Grosso M, Palumbo I, et al. Allele-specific transcriptional activity of the variable number of tandem repeats of the inducible nitric oxide synthase gene is associated with idiopathic achalasia. United European Gastroenterol J 2017;5:200-7. Crossref

3. Sadowski D, Ackah F, Jiang B, Svenson LW. Achalasia: incidence, prevalence and survival. A population-based study. Neurogastroenterol Motil 2010;22:e256-61. Crossref

4. Francis D, Katzka D. Achalasia: update on the disease and its treatment. Gastroenterology 2010;139:36974. Crossref

5. Pohl D, Tutuian R. Achalasia: an overview of diagnosis and treatment. J Gastrointestin Liver Dis 2007; 16:297-303.

6. Pandolfino J, Ghosh S, Rice J, Clarke JO, Kwiatek MA, Kahrilas PJ. Classifying esophageal motility by pressure topography characteristics: a study of 400 patients and 75 controls. Am J Gastroenterol 2008;103:27-37. Crossref

7. Weijenborg PW, van Hoeij FB, Smout AJ, Bredenoord AJ. Accuracy of hiatal hernia detection with esophageal high-resolution manometry. Neurogastroenterol Motil 2015;27:293-9. $\underline{\text { Crossref }}$

8. Pandolfino J, Gawron A. Achalasia: a systematic review. JAMA 2015;313:1841-52. Crossref

9. Howard P, Maher L, Pryde A, Cameron EW, Heading RC. Five year prospective study of the incidence, clinical features, and diagnosis of achalasia in Edinburgh. Gut 1992;33:1011-15.

10. de Oliveira JM, Birgisson S, Doinoff C, et al. Timed barium swallow: a simple technique for evaluating esophageal emptying in patients with achalasia. Am J Roentgenol 1997;169:473-9. $\underline{\text { Crossref }}$

11. Butin JW, Olsen AM, Moersch HJ, Code CF. A study of esophageal pressures in normal persons and patients with cardiospasm. Gastroenterology 1953;23: 278-93.

12. Silny J. Intraluminal multiple electric impedance procedure for measurement of gastrointestinal motility. Neurogastroenterol Motil 1991;3:151-62. $\underline{\text { Crossref }}$ 
13. Fox M, Hebbard G, Janiak P, et al. High-resolution manometry predicts the success of oesophageal bolus transport and identifies clinically important abnormalities not detected by conventional manometry. Neurogastroenterol Motil 2004;16:533-42. $\underline{\text { Crossref }}$

14. Grübel C, Hiscock R, Hebbard G. W1900: value of spatiotemporal representation of manometric data. Gastroenterology 2008;134(Suppl 1):A-729. Crossref

15. Bogte A, Bredenoord AJ, Oors J Siersema PD, Smout AJ. Reproducibility of esophageal high-resolution manometry. Neurogastroenterol Motil 2011;23:e2716. $\underline{\text { Crossref }}$

16. Kahrilas P, Bredenoord A, Fox M, et al. The Chicago Classification of esophageal motility disorders, v3.o. Neurogastroenterol Motil 2015;27:160-74. $\underline{\text { Crossref }}$

17. Pandolfino JE, Kwiatek MA, Nealis T, Bulsiewicz W, Post J, Kahrilas PJ. Achalasia: a new clinically relevant classification by high-resolution manometry. Gastroenterology 2008;135:1526-33.

18. Bogte A, Bredenoord AJ, Oors J, Siersema PD, Smout AJ. Normal values for esophageal high-resolution manometry. Neurogastroenterol Motil 2013;25:762e579. $\underline{\text { Crossref }}$

19. Lee J, Kim N, Kim SE, et al. Clinical characteristics and treatment outcomes of 3 subtypes of achalasia according to the Chicago Classification in a tertiary institute in Korea. J Neurogastroenterol Motil 2013; 19:485-94 Crossref

20. Rohof WO, Salvador R, Annese V, et al. Outcomes of treatment for achalasia depend on manometric subtype. Gastroenterology 2013;144:718-25. Crossref

21. Richter JE. Achalasia: new diagnostic tests and treatments. Expert Opin Orphan Drugs 2015;3:403-17. $\underline{\text { Crossref }}$

22. Ratuapli SK, Crowell MD, DiBaise JK, et al. Opioidinduced esophageal dysfunction (OIED) in patients on chronic opioids. Am J Gastroenterol 2015;110: 979-84. Crossref

23. Kraichely RE, Arora AS, Murray JA. Opiate-induced oesophageal dysmotility. Aliment Pharmacol Ther 2010;31:601-6. $\underline{\text { Crossref }}$

24. Ravi K, Murray JA, Geno DM, Katzka DA. Achalasia and chronic opiate use: innocent bystanders or associated conditions? Dis Esophagus 2016;29:15-21. $\underline{\text { Crossref }}$

25. O'Neill OM, Johnston BT, Coleman HG. Achalasia: a review of clinical diagnosis, epidemiology, treatment and outcomes. World J Gastroenterol 2013;19:580612. $\underline{\text { Crossref }}$

26. Vela MF. Management strategies for achalasia. Neurogastroenterol Motil 2014;26:1215-21. Crossref
27. Pasricha PJ, Ravich WJ, Hendrix TR, Sostre S, Jones $\mathrm{B}$, Kalloo AN. Intrasphincteric botulinum toxin for the treatment of achalasia. N Engl J Med 1995;332: 774-8. $\underline{\text { Crossref }}$

28. Campos GM, Vittinghoff E, Rabl C, et al. Endoscopic and surgical treatments for achalasia: a systematic review and meta-analysis. Ann Surg 2009;249:4557. $\underline{\text { Crossref }}$

29. Vaezi M, Pandolfino J, Vela M. ACG clinical guideline: diagnosis and management of achalasia. Am J Gastroenterol 2013;108:1238-49. Crossref

30. Lynch K, Pandolfino J, Howden C, Kahrilas PJ. Major complications of pneumatic dilation and Heller myotomy for achalasia: single-center experience and systematic review of the literature. Am J Gastroenterol 2012;107:1817-25. Crossref

31. Moonen A, Annese V, Belmans A, et al. Long-term results of the European achalasia trial: a multicentre randomised controlled trial comparing pneumatic dilation versus laparoscopic Heller myotomy. Gut 2016;65:732-9. Crossref

32. Boeckxstaens G, Annese V, Varannes S, et al. Pneumatic dilation versus laparoscopic Heller's myotomy for idiopathic achalasia. N Engl J Med 2011;364: 1807-16. $\underline{\text { Crossref }}$

33. Vanuytsel T, Lerut T, Coosemans W. Conservative management of esophageal perforations during pneumatic dilation for idiopathic esophageal achalasia. Clin Gastroenterol Hepatol 2012;10:142-9. Crossref

34. Gaissert H, Lin N, Wain JC, Fankhauser G, Wright CD, Mathisen DJ. Transthoracic Heller myotomy for esophageal achalasia: analysis of long-term results. Ann Thorac Surg 2006;81:2044-9. $\underline{\text { Crossref }}$

35. Rawlings A, Soper NJ, Oelschlager B, et al. Laparoscopic Dor versus Toupet fundoplication following Heller myotomy for achalasia: results of a multicenter, prospective, randomized-controlled trial. Surg Endosc 2012;26:18-26. Crossref

36. Kilic A, Schuchert MJ, Pennathur A, Gilbert S, Landreneau RJ, Luketich JD. Long-term outcomes of laparoscopic Heller myotomy for achalasia. Surgery 2009;146:826-31. Crossref

37. Inoue $\mathrm{H}$, Minami $\mathrm{H}$, Kobayashi $\mathrm{Y}$, et al. Peroral endoscopic myotomy (POEM) for esophageal achalasia. Endoscopy 2010;42:265-71. Crossref

38. Bechara R, Onimaru M, Ikeda H, Inoue H. Per-oral endoscopic myotomy, 1000 cases later: pearls, pitfalls, and practical considerations. Gastrointest Endosc 2016;84:330-8. Crossref

39. Barbieri LA, Hassan C, Rosati R, Romario UF, Correale L, Repici A. Systematic review and metaanalysis: efficacy and safety of POEM for achalasia. 
United European Gastroenterol J 2015;3:325-34. Crossref

40. Zhang XC, Li QL, Xu MD, et al. Major perioperative adverse events of peroral endoscopic myotomy: a systematic 5-year analysis. Endoscopy 2016;48:96778. Crossref

41. Bhayani NH, Kurian AA, Dunst CM, Sharata AM, Rieder E, Swanstrom LL. A comparative study on comprehensive, objective outcomes of laparoscopic Heller myotomy with per-oral endoscopic myotomy (POEM) for achalasia. Ann Surg 2014;259:1098-103. Crossref
42. Kumbhari V, Tieu AH, Onimaru M, et al. Peroral endoscopic myotomy (POEM) vs laparoscopic Heller myotomy (LHM) for the treatment of Type III achalasia in 75 patients: a multicenter comparative study. Endosc Int Open 2015;3:E195-201. $\underline{\text { Crossref }}$

43. Khashab MA, Messallam AA, Onimaru M, et al. International multicenter experience with peroral endoscopic myotomy for the treatment of spastic esophageal disorders refractory to medical therapy (with video). Gastrointest Endosc 2015;81:1170-7. Crossref 